\title{
Vendo o outro através da tela: cinema, humanização da educação médica e Medicina de Família e Comunidade.
}

\section{Seeing the other through the screen: movies, humanization of medical education and Family and Community Medicine.}

Gustavo de Araúijo Porto Landsberg

"O que conduz o mundo é o espírito, e não a inteligência."

Antoine de Saint-Exupéry

\section{Resumo}

O desenvolvimento tecnológico sem precedentes observado no último século e início deste ampliou os horizontes da ciência médica exponencialmente, tornando o conteúdo a ser contemplado pelas faculdades praticamente inviável. A incorporação desse conhecimento nos curriculae deu-se em detrimento das ciências humanas, outrora abordadas rotineiramente nas faculdades de medicina de todo o mundo. A negligência da humanização da educação médica poderá deixar de dotar aos futuros médicos os recursos afetivos necessários ao estabelecimento de uma relação médico-paciente satisfatória. Este estudo propôe avaliar o uso do cinema na humanização do olhar dos graduandos, provendo aos mesmos a capacidade de reflexão e empatia para com seus pacientes. Foram eleitos três documentários que se correlacionam indiretamente com temas referentes à Medicina de Família e Comunidade: saúde do trabalhador, mental e comunitária. Após a exibição para pequenos grupos de alunos, houve uma discussão multidisciplinar com abordagem de diversos temas relevantes à prática médica. Finalmente, aplicou-se questionários onde os alunos avaliavam a importância da experiência em sua formação, bem como respondiam questões sobre seu contato com as artes e interesses pessoais. Todos os alunos consideraram o grau de correlação dos filmes escolhidos com a prática médica boa ou ótima. Questionados sobre a relevância dos temas abordados em suas formações, 94,1\% deles responderam bom ou ótimo. Um mesmo percentual considerou também boa ou ótima a inclusão curricular da metodologia. Observou-se que os alunos avaliados lêem menos que a média nacional, e uma quantidade considerável deles não se interessa ou nunca foi ao teatro, exposição de arte ou espetáculo de dança. O cinema, no entanto, apresentou grande popularidade - confirmando seu potencial como recurso didático humanizador.

Palavras-chave: Medicina de Família e Comunidade; Cinema Como Assunto; Materiais de Ensino; Educação Médica; Humanidades.
Key Words: Fanily and Community Medicine; Motion Pictures as a Discipline; Teaching Materials; Medical Education; Humanities.

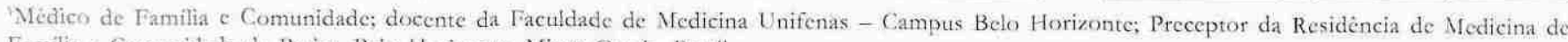
Familia e Comunidade de Betim, Belo Horizonte, Minas Gerais, Brasil. 


\section{Abstract}

The unprecedented teclonological development observed in the last century and beginning of this one has expanded the borizons of the medical science exponentially, making the content to be envisaged by the colleges practically unfeasible. The incorporation of this knowledge in the curricula took place in detriment to buman sciences, formerly included as a routine in the schools of medicine all over the world. Negligence of the hunnamization of medical education may keep from endowing future physicians with the affective resaurces necessary to the establishment of a satisfactory physical-patient relationship. This study proposes evaluating the use of motion pictures in the bumanization of the way graduates see patients, providing them with capability and empathy toward their patients. Three documentaries that correlate indirectly with themes relative to Family and Community Medicine were selected: worker's mental and community bealth. After screening to small groups of students, there was a multidisciplinary discussion covering all the several themes relevant to the medical practice. Finally, questionnaires were applied where the students evaluated the importance of the experience in their education, as well as replied to questions about their contact with arts and personal interests. All the students considered the level of correlation of the motion pictures chosen as a good or excellent medical practice. Questioned on the relevance of the themes covered in their education, $94.1 \%$ of them answered good or fine. The same percentage considered the curricular inclusion of methodology also good or fine. It was observed that the students evaluated read less than the national average, and a considerable amount of them is not interested in or bas never been to a theater, an at exposition or a dance slow. The movies, bowever, proved to be very papular confirming its potential as a bumanizing teacling resource.

\section{Introdução}

Houve uma época em que médicos eram intelectuais, estudiosos não apenas da matéria médica, mas também das ciências humanas. História, Filosofia, Sociologia, Antropologia, Psicologia e Direito eram disciplinas que faziam efetivamente parte do currículo das faculdades. Houve um tempo em que médicos se dedicavam também às artes. Henle fez uso de seu talento para desenhar as estruturas que observava ao microscópio e publicar seus livros. Além de desenhista, era violinista e poeta. Pasteur também era pintor, especialista em retratos. Freud ganhou prèmios como escritor ${ }^{1}$. Muitos médicos brasileiros revelaram seus talentos nas artes, como Guimarães Rosa, Moacyr Scliar, Pedro Nava.

Entretanto, o mundo mudou. Largos são os passos dados pela ciência nas últimas décadas. O conhecimento médico amplia-se de forma vertiginosa, tornando o conteúdo a ser contemplado pelas faculdades de medicina quase impraticável - e os curriculae tiveram que preconizar as disciplinas de conteúdo técnico em detrimento das humanida$\operatorname{des}^{2,3}$.

Os atuais cursos de medicina caracterizam-se pela racionalizaçào e cientificismo. Obviamente, trata-se de um avanço: a medicina deve sempre se pautar pela ciència. Entretanto, deixar de levar em conta as múltiplas nuances de subjetividade inerentes ao ser humano é incorrer em erro. Não saber reconhecer a interferência de variáveis ambientais, sociais e individuais no processo de saúde e adoecimento de cada paciente é diagnosticar e tratar de forma superficial, padronizante. E no âmbito da Medicina de Familia e Comunidade, disciplina recente ou até mesmo ainda ausente em muitas grades curriculares de faculdades brasileiras, esse tipo de abordagem holística e orientada para o individuo é crucial.

Obviamente, nào se pode pretender que a maior parte dos graduandos volte a ler Aristóteles ou Tolstoi, uma vez que já se encontram sobrecarregados por outros textos médicos que, usualmente, os interessam muito mais. Por essa razão, o cinema - de linguagem mais dinàmica e cotidiana - pode ser uma ferramenta útil. Filmes de arte e documentários normalmente não fazem parte do gosto comum e nem sempre estão associados ao entretenimento. Tais filmes poderão ter um papel importante na formação humanística dos alunos, sensibilizando-os para questões individuais íntimas, convocando-os a experiências de empatia com diferentes personagens e realidades.

Muito já se pesquisou sobre o uso das artes na formação humanística dos estudantes de medicina. Música, 
teatro, dança, pintura e desenho, escultura, literatura, cinema - tudo já foi experimentado, com resultados diversos e, em geral, entusiasmantes ${ }^{4,5,6,78}$. Alunos que aprenderam a observar peças de arte em museus desenvolveram maiores habilidades de observação de lesões dermatológicas?. O uso curricular de artes visuais, literatura e música melhorou as habilidades dos alunos nos processos de comunicação médico-paciente e decisão terapêutica ${ }^{9}$.

Entretanto, chama a atenção a ausência de estudos que avaliem, de forma mais objetiva, os reais interesses dos alunos brasileiros, a intimidade que eles têm com o mundo artístico em todas as suas manifestações e, finalmente, a visão que eles têm sobre a proposta de aplicação curricular dessas estratégias pedagógicas.

Este artigo, antes de pretender ser um artigo, era apenas um desejo de despertar, num grupo pequeno de alunos, o interesse em se aprofundar um pouco mais no vasto universo da chamada condição humana. Posteriormente, tornou-se uma (quase) necessidade de relatar a colegas espalhados por todo o país uma experiência exitosa e entusiasmante. No fim, creio, tornou-se principalmente um convite. Um convite a repensarmos que futuro desejamos para a profissão a que optamos por dedicar nossas vidas.

\section{Objetivo}

Avaliar o uso de filmes de arte e documentários como ferramenta na formação humanística dos alunos, no contexto da Medicina de Familia e Comunidade.

\section{Justificativa}

Por se comunicar direta, veloz e sensorialmente com o espectador, o cinema se adapta bem à linguagem contemporânea à qual o aluno está habituado. $\mathrm{O}$ uso de filmes que contenham um olhar mais subjetivo e que levam à reflexão - e não somente ao entretenimento - pode ser um meio de aumentar a capacidade do aluno de compreender e ter uma visão crítica dos múltiplos fatores sociais, ambientais, familiares e culturais que terão impacto na saúde de seu paciente. Sem tal compreensão, uma boa relação médico-paciente dificilmente se estabelece.
Citando Blasco": "Um médico sem humanismo não será propriamente médico; na melhor das hipóteses, trabalhará como um mecânico de pessoas."

\section{Metodologia}

Pequenos grupos de alunos (10 a 20) do primeiro e do sexto período da Faculdade de Medicina da Universidade José do Rosário Vellano (UNIFENAS-BH) foram convidados a participar de uma atividade extracurricular optativa, onde seria exibido um filme e, posteriormente, haveria uma discussão multidisciplinar com a participação de uma psicanalista e um profissional da área de cinema. Aproximadamente $50 \%$ dos convidados se interessaram.

Foram selecionados inicialmente três filmes que abordam indiretamente temas referentes à prática médica na Atenção Primária à Saúde: saúde do trabalhador, mental e comunitária. Após cada sessão, que contava, em média, com cinco a 12 alunos, promoveu-se uma discussão onde os mesmo foram incentivados a externar suas impressões e os sentimentos despertados pelo filme. Os profissionais convidados fizeram também pontuações complementares e responderam a perguntas. Durante as conversas, foram tomadas notas a respeito dos assuntos abordados.

Terminada a atividade, os alunos preencheram um questionário anônimo com questões fechadas e diretas, como: "avalie o grau de correlação do filme assistido com a prática médica", ou "avalie a utilidade do cinema como forma de educação médica", com respostas contendo cinco graduações, de acordo com a escala de Likert: péssimo/ ruim/indiferente/bom/ótimo. Na segunda parte do questionário, procurou-se conhecer que formas de expressão artística despertam maior interesse nos alunos, que deveriam assinalar, dentre teatro, exposições de artes plásticas (pintura, fotografia, escultura), shows de música, dança, literatura e cinema, com quais costumam conviver e com que frequência.

Havia, ainda, um espaço final para comentários e sugestões $~-$ de onde foram tiradas citações para a análise qualitativa. 


\section{Filmes Selecionados}

- Powaqqatsi, 1988.

Produzido por Francis Ford Coppola e Geoge Lucas, dirigido por Godfrey Reggio, com trilha sonora de Philip Glass.

É o segundo de uma trilogia, que trata do impacto do desenvolvimento tecnológico sobre o homem, nesse filme, em especial, sobre os países do hemisfério sul. Sem narrativas ou diálogos, uma linha de raciocínio é tecida em perfeita harmonia com a trilha sonora envolvente e uma fotografia magistral.

- Estamira, 2005.

Esse premiado documentário de Marcos Prado foi filmado no Aterro Sanitário de Jardim Gramacho, no Rio de Janeiro. Tem como protagonista Estamira, paciente psicótica que faz do lixo seu meio de vida.

O filme dá amplo espaço a um discurso ora ininteligível, ora carregado de uma lancinante lucidez, onde a personagem expõe de forma mística, porém extremamente racional, sua visão de mundo, sua relação com o ambiente, com o outro, com Deus.

$\mathrm{O}$ documentário é ambíguo na medida em que nos transpõe, ao mesmo tempo, ao mundo aparentemente caótico e desconexo da psicose, e à uma aguda e crua percepção da realidade que nos permeia, em sua forma mais suja e cruel - universos a que nós, homens médios, diariamente fechamos os olhos.

- Edifício Master, 2002.

Documentário brasileiro de Eduardo Coutinho. Durante sete dias, uma equipe de cinema filmou o cotidiano dos moradores do Edificio Master, situado em Copacabana, a um quarteirão da praia. $\mathrm{O}$ prédio tem 12 andares, com 276 apartamentos conjugados, onde moram cerca de 500 pessoas. Eduardo Coutinho e sua equipe entrevistaram 37 moradores e conseguiram extrair histórias íntimas e reveladoras de suas vidas, histórias que ocorrem com claustrofóbica proximidade, ainda que com raros pontos de interseção. Um retrato cru da solidão da vida urbana contemporânea.

\section{Resultados}

\subsection{Análise Qualitativa}

Surpreendentemente, houve grande satisfação dos alunos com a experiência. Um dos alunos escreveu: "é a primeira vez que assisto a um documentário, não esperava me interessar tanto" (aluno A). Houve grande envolvimento por parte dos participantes e ocorreram ricas discussões onde os mais diversos temas foram abordados, grande parte deles diretamente relacionados à medicina. A participação de pessoas de diferentes áreas enriqueceu os pontos de vista. No feedback, os alunos se mostraram entusiasmados e ressaltaram o impacto que tal experiència poderá ter em suas formações, como se pode perceber em seus comentários:

"Na minha opinião, esta atividade foi muito válida, e trará influências na minha vida profissional” (Aluno B).

"O filme me fez ver o paciente além de simplesmente uma pessoa que apresenta-se ao consultório com uma queixa e quer solucioná-la. Ele está além das palavras que solta ali. Isso me fez pensar em ter uma sensibilidade maior para com ele e refletir sobre isso. Essa didática só acrescenta a nós, acadêmicos, como profissionais e pessoas" (Aluno C).

"A influência de qualquer forma de arte no processo de desenvolvimento da formaçào médica é relevante e eficaz, uma vez que estimula a construção de uma visào mais humana e realista das pessoas, além de conduzir a reflexão e conscientização" (Aluno D).

A seguir, serão citados alguns dos temas discutidos após a exibição de cada filme.

Powaqqatsi: alunos do sexto periodo do ambulatório de Saúde da Família e Comunidade falaram sobre capitalismo e exclusào social; o ambiente, o trabalho e suas repercussões sobre a saúde; aspectos sociais da loucura; poesia e arte e suas correlaçōes com a medicina; globalizaçào, consumismo, TV e aculturação. Religiâo, etilismo, drogadição e suas telações com a miséria. Também surgiram temas médicos, como DORT, osteoartrose, TOC, psicose, depressão, asma, relação médico-paciente, semiologia, fases do ciclo vital. Houve inclusive alusões a diversos casos clínicos 
que haviam sido vistos no ambulatório naquele mesmo dia.

Estamira: outras duas turmas do mesmo ambulatório de Saúde da Família e Comunidade, promoveram riquíssima conversa sobre os mais diversos temas. Consumismo, desperdício, sustentabilidade, educação ambiental e seus impactos sobre a saúde. Educação médica. Ética. Falouse sobre a dinâmica familiar no processo de adoecimento, a importância da familia e de abordagens não farmacológicas no cuidado dos pacientes. Discutiram-se racismo, preconceito, exclusão social. Ressaltou-se a importância de se fazer uma boa anamnese, extraindo da história do paciente pistas para uma melhor compreensão de suas doenças.

Edificio Master: os alunos do primeiro periodo presentes nesta sessão cursavam a disciplina Práticas Médicas Comunitárias I, realizada no ambiente de uma Unidade Básica de Saúde, com realização de visitas domiciliares e entrevistas a usuários. Assim, foi feita grande associação com alguns temas abordados pela disciplina: trabalho multidisciplinar, conceitos de saúde e doença, fases do ciclo vital, genograma, ecomapa, abordagem familiar. Falou-se sobre a semelhança entre um documentário e uma entrevista clínica, onde personagens encontram espaço para terem escutadas suas queixas, anseios, medos, traumas e desejos. Da mesma forma, durante a atividade, os graduandos encontraram ambiente favorável para expressarem suas expectativas em relação ao curso, bem como fazerem uma crítica sobre suas próprias condições. Alunos de outras cidades falaram sobre a experiência de deixar a casa dos pais e ter de refazer seus vínculos sociais, assumindo novas responsabilidades.

\subsection{Análise Quantitativa}

Nesta experiência inicialmente informal, preocupouse menos com a rigidez dos números e mais com a elencagem dos filmes e suas eventuais repercussões no graduandos. Ainda assim, tentou-se continuar fiel à ideja de se fazer uma análise crítica dos resultados, bem como a de conhecer um pouco da intimidade dos acadêmicos com o universo da arte.
Foi convidado um total de 52 alunos, de quatro diferentes turmas, dos quais 32 compareceram e responderam ao questionário (61,5\%). Além disso, outros dois jovens de outra turma (convidados pelos próprios alunos) compareceram e também responderam aos questionários, totalizando 34.

Os questionários traziam perguntas diretas, como: "avalie o grau de correlação do filme assistido com a prática médica", com respostas contendo cinco graduações, de acordo com a escala de Likert: péssimo/ruim/indiferente/bom/ ótimo.

Todos os alunos consideraram o grau de correlação dos filmes escolhidos com a prática médica bom ou ótimo (tabela 1). Questionados sobre a relevância dos temas abordados em suas formações, 94,1\% deles responderam bom ou ótimo. Um mesmo percentual considerou também bom ou ótimo a inclusão curricular da metodologia.

Quando perguntou-se aos alunos sobre a importância do estudo de ciências humanas no contexto médico, apenas um aluno se manifestou contrariamente $(2,9 \%)$.

Noventa e um vírgula sete por cento dos participantes julgaram boa ou ótima a participação de profissionais de outras áreas nas discussões.

Questionados sobre outras formas de expressão artística que poderiam ser usadas na formação acadêmica, os mais citados foram teatro, literatura e fotografia, nessa ordem.

Na segunda parte do questionário (tabela 2), procurou-se conhecer um pouco dos interesses dos alunos e a proximidade deles com as artes. Infelizmente, as respostas falam por si.

O percentual dos alunos que declarou não se interessar ou nunca ter frequentado uma peça de teatro, uma exposição de arte ou um espetáculo de dança foram, respectivamente, $20,5 \%, 38,2 \%$ e $70,5 \%$.

Uma média de 3,14 livros de literatura não médica é lida por eles anualmente. A média nacional divulgada pelo Instituto Pró-livro em 2008 foi de 4,7 livros/ano ${ }^{10}$.

Somente cinema teve popularidade entre os alunos: declaram frequentá-lo semanal ou mensalmente $91,2 \%$ deles. 


\section{Conclusão}

Apesar do número pequeno de participantes, que limita a extrapolação dos resultados observados, e, apesar de não se ter realizado um análise estatística com manipulação cega dos dados, o presente estudo nos permite delinear uma tendência.

Primeiramente, a falta de intimidade dos alunos com as ciências humanas e as artes em geral, excetuando-se o cinema.

Em segundo, a receptividade dos alunos, que se mostram dispostos a aprofundar o nível de discussão do conhecimento médico para além do cientificismo puro e simples. Eles demonstraram, além disso, a capacidade de perceber lacunas em suas formações e pontuaram a relevância do conhecimento das diferenças individuais e da contextualização de cada paciente, permitindo entender melhor os fatores que irão interferir em sua saúde.

Os diversos temas que emergiram das discussões, por sua abrangência e relevância, revelam êxito na seleção dos filmes. Talvez a preferência por mostrar documentários nacionais ou que se relacionem ao Brasil tenha contribuido para aumentar o grau de identificação dos alunos com as personagens e suas histórias.

Levar arte ao aprendizado médico pode ser uma experiência enriquecedora e relativamente fácil, tanto para o aluno quanto para o professor. Recuperar o humanismo na prática da medicina não se trata de uma utopia, mas sim de uma necessidade real.

É possivel expandir o conhecimento dos alunos para novos campos e com isso provê-los com ferramentas que agucem, ampliem e humanizem seu olhar.

E a capacidade de observar é a verdadeira arte do bom médico.

\section{Referências}

1. Garrison, FH. History of Medicine 2 ed. [s.1.]:Saunders Company; 1917. 905 p. [falta o local]

2. Blasco, PG. Cinema para o Estudante de Medicina: um recurso afetivo/efetivo na educação humanística. Rev Bras Educ Médica. 2005; (29): 24-38.

Tabela 1. Grau de correlação do filme com a prática médica:

\begin{tabular}{|c|c|c|c|c|c|}
\hline & Péssimo & Ruim & Indiferente & Bom & Ótimo \\
\hline Correlação com a prática & & & & 19 & 15 \\
\hline Relevância do Tema & & & 2 & 8 & 24 \\
\hline Inclusão curricular da metodologia & & & 2 & 11 & 21 \\
\hline Importância do estudo das ciências humanas & & 1 & 1 & 10 & 22 \\
\hline Participação multidisciplinar & & 1 & 2 & 1 & 18 \\
\hline
\end{tabular}

Tabela 2. Interesse e proximidade dos alunos com as artes:

\begin{tabular}{lccccc}
\hline & Nunca & Anual & Semestral & Mensal & Semanal \\
\hline Teatro & 7 & 8 & 18 & & 1 \\
Exposição de artes plásticas & 13 & 18 & 2 & 1 & \\
Dança & 24 & 8 & 2 & 24 & 5 \\
Cinema & & 1 & 4 & 24 & 5 \\
\hline
\end{tabular}


3. Grant, VJ. Making Room for Medical Humanities. J Med Ethics: Medical Humanities 2002; (28): 45-48.

4. Scott, P Ann, e. The relationship between the arts and medicine. J Med Ethics: Medical Humanities 2000; (26): 3-8.

5. Blasco, PG. Literature and Movies for Medical Students.

Fam Med 2001; 33 (6): 426-8.

6. Reilly JM, Ring J, Duke L. Visual Thinking Strategies: A New Role for Art in Medical Education. Fam Med 2005; 37(4): 250-2.

7. Meites E, Bein S, Shafer A. Researching medicine in context: the Arts and Humanities Medical Scholars Program. J Med Ethics: Medical Humanities 2003; (29): 104-108.

8. Weber, CM. Silk, H. Movies and Medicine: An Elective Using Film to Reflect on the Patient, Family and Illness. Fam Med 2007; 39(5): 317-9.

9. Arts in health: a review of the medical literature. Staricoff, RL. Arts Council England, 2004. Disponivel em www.artscouncil.org.uk.

10. Instituto Pró-Livro (2008), "Retratos da Leitura no Brasil". Disponível em: http://www.prolivro.org.br

Agradecimentos:

A Érika Finelli Mendez (psicóloga psicanalista) e Alexandre Baxter (Produtora de Vídeo Olho de Peixe), por multiplicarem nossos olhares.

\section{Endereço para Correspondência:}

Rua Líbano, 66 - Bairro Itapoã

Belo Horizonte MG

CEP: $31710-030$.

\section{Endereço eletrônico:}

gustavolandsberg@gmail.com 